\title{
SEXUALIDADE E AMOR NA VELHICE
}

\author{
Sueli Souza dos Santos ${ }^{1}$ \\ Sergio Antonio Carlos ${ }^{2}$
}

\section{Resumo}

Este trabalho é o resultado de uma pesquisa sobre a sexualidade e o amor na velhice, tendo como objetivo analisar - através da interação da psicanálise com a análise da produção dos sentidos na perspectiva discursiva - os aspectos da sexualidade do ponto de vista pulsional. Para isso, analisamos as implicações inconscientes que estão em jogo nessa problemática. Utilizamos como instrumento metodológico a produção de efeitos de sentidos baseada na Análise do Discurso (AD) da escola francesa que tem como fundador Michel Pêcheux, mais especificamente na terceira fase desse autor, levando em consideração as teorizações de Althier-Revuz, de Orlandi e de Teixeira. Contribuem para este trabalho também os fundamentos da psicanálise de Freud no que se refere ao inconsciente e à sexualidade, e de Lacan, no que se refere ao sujeito do discurso na sua relação com o Outro. Concluímos que as questões ligadas à sexualidade e ao amor na velhice se revelam na heterogeneidade discursiva, "com as não-coincidências do dizer". A sexualidade insiste em se apresentar de outra maneira, sob a forma de fantasias, desejos e sonhos. Com a velhice não se verifica a suposta desistência da vida sexual e amorosa, pois esta é pulsional, sendo, por isso mesmo, um elemento vital inesgotável.

Palavras-chave: Sexualidade. Velhice. Heterogeneidade do Discurso.

\footnotetext{
${ }^{1}$ Psicanalista, Mestre em Psicologia Social e Institucional pela UFRGS e Doutoranda em Educação na UFRGS. E-mail: susantos@terra.com.br

2 Assistente Social, Doutor em Serviço Social pela Pontifícia Universidade Católica (PUC/SP) e professor do Programa de Pós-Graduação em Psicologia Social do Instituto de Psicologia da UFRGS. E-mail: sacarlos@ufrgs.br
} 


\section{Introdução}

A trajetória de vida do ser humano é um somatório das experiências vividas, dos valores, das metas, da compreensão e das interpretações pessoais que cada um tem do mundo em que vive. Estamos, em nossa existência humana, condicionados às determinações da hereditariedade, do social e do cultural, como geradores de nossas escolhas e filosofia de vida.

A velhice, tal como a infância, a juventude e a idade adulta, é circunscrita como uma etapa de transformação, tanto física como biológica, emocional e sexual. A forma como cada pessoa envelhece está determinada por suas condições subjetivas, incluindo-se aí a forma como foi vivida sua história pessoal em todos os períodos da existência e também está atrelada às condições socioculturais.

Os estudos desenvolvidos por Beauvoir (1976) apontam que a velhice tem uma dimensão existencial. A relação do indivíduo com o tempo se modifica tendo reflexo na sua relação com o mundo e com sua própria história. Para essa autora, o ser humano não vive nunca em estado natural, portanto, na velhice, como em qualquer idade, seu estatuto lhe é imposto pela sociedade à qual pertence.

O lugar destinado ao velho está condicionado pela atitude prática e ideológica da sociedade em relação a ele. Isso significa que, descrevendo de maneira analítica os diversos aspectos que a velhice tem, tais como as perdas funcionais e orgânicas, isso implica considerar, por vezes, que a mesma não é um fato estático, mas o resultado e o prolongamento de um processo de vida.

Os estudos voltados para a velhice, em sua maioria, referem-se às perdas, sejam elas de capacidades físicas, produtivas, intelectuais ou econômicas. Alguns autores, como Cummings e Henry, ${ }^{3}$ estudados por Sánchez, chegam a propor uma teoria do desengajamento, afirmando que as pessoas por si mesmas diminuem sua interação social e que essa ação é funcionalmente vantajosa para elas e para a sociedade. Essa teoria afirma que as pessoas estão prontas para se retirarem quando se dão conta do curto período de tempo que lhes resta para viver e quando percebem que vão perdendo energia e vitalidade para manter suas funções. Por outro lado, os velhos buscam a oportunidade de retirar-se das demandas da sociedade para con-

3 CUMMINGS, E.; HENRY, W. Growing Old: the process of disengagement. New York: Basic Books, 1961. Apud SANCHEZ, 1999. P. 81. 
templar sossegadamente o significado da vida e da morte. Por isso, o isolamento se converte em algo aceitável e em uma conduta adaptativa, em que a sociedade e o indivíduo compartilham a responsabilidade da separação.

A velhice, como um fenômeno de múltiplo significado, decorre de um contexto fragmentado das experiências de vida, na sua complexidade cultural. O processo do envelhecimento está sempre associado, invariavelmente, ao fim da vida, à morte, o que talvez nos leve a associar a isso os quadros de depressão e angústia que surgem aos primeiros sinais de perda de vitalidade ou com a aposentadoria.

Seguindo esse raciocínio, Mannoni (1995) vai dizer que o velho, destituído de um lugar de importância como ser vital e produtivo para o mercado de trabalho, vendo-se limitado na sua possibilidade de intervenção sobre o seu meio, retira-se para um mundo de depressão. A angústia decorrente desse processo leva-o a um ciclo que vai da desconfiança paranóica aos estados de euforia, acompanhados, muitas vezes, de perda das funções vitais, seguindo-se a decadência do corpo, como punição frente à proximidade da idéia de morte. Assim, o velho não sabe mais seu lugar na vida social, entendendo-se o social como família, amigos e grupos de convivência.

Não se pode afirmar, no entanto, que o velho perca a capacidade de amar ou de ter uma vida sexual, como se isso fosse prerrogativa dos jovens, como se o interesse sexual ou amoroso causasse um certo horror, fosse algo aberrante, que não possa ser aceito. Resgatar o direito a uma vida sexual do velho implica poder pensar o amor em suas formas de transformação libidinal, ou seja, outras formas de amor que passam pela ternura, pelos contatos físicos que erogenizam o corpo, como o olhar, o toque, a voz, redescobrindo as primeiras formas de amor do ser humano. O velho não deixa de amar, mas reinventa formas amorosas. A relevância do estudo do amor na velhice está nesta perspectiva: de pensar outro enfoque para a vida do velho, não partindo de suas perdas, mas, ao contrário, das possibilidades criativas dadas pelo vivido, pelo sofrido e pelo acumulado nas experiências amorosas e, por isso mesmo, reengendrando a vida em suas infinitas possibilidades, independentemente da proximidade real da morte.

\section{Sentido Sexual de Nossos Atos}

Ao falar em sentido sexual de nossos atos, estamos nos reportando aos conceitos psicanalíticos. Para Freud (1969), os atos falhos, os equívo- 
cos e os sonhos estão encobrindo sentidos que refletem conteúdos inconscientes, ou seja, os atos involuntários, aquilo que nos escapa: por isso mesmo, têm um sentido. Encontrar um sentido para as palavras e as condutas que nos escapam produz a revelação de um desejo até então velado.

A propriedade erógena pode ligar-se a algumas partes do corpo, marcadas pelas primeiras experiências prazerosas, como chupar, sugar, ou a qualquer outro ponto da pele ou da mucosa, podendo tomar a seu cargo as funções de zona erógena. Os estímulos, mais do que a natureza das partes estimuladas do corpo, determinarão a produção da sensação prazerosa. $\mathrm{Na}$ infância, o alvo sexual consiste em provocar a satisfação mediante a estimulação da zona erógena que foi escolhida. A satisfação será vivenciada anteriormente para transformar-se em necessidade a ser repetida.

Os sentidos que buscamos relacionam-se a acontecimentos de hoje e com todos os acontecimentos do passado e, ainda com um hipotético acontecimento inicial, que jamais ocorreu, ou seja, a primeira experiência de satisfação, quando a relação com o objeto que causava essa satisfação era de completude, ou seja, quando mãe e bebê pareciam ser uma só coisa. O sentido inconsciente do ato que realizamos se funda no fato de que esse ato substituía a todos os atos passados de nossa história ou, rigorosamente, a todo o primeiro ato ideal na origem da nossa história, tentando, portanto, produzir, em sua substituição, um ideal não realizado.

Chamamos sexual toda conduta que, partindo de uma região erógena do corpo (boca, ânus, olhos, voz, pele) e apoiando-se numa fantasia, proporciona algum tipo de prazer. O prazer de mamar do bebê, por exemplo, seu prazer da sucção, do ponto de vista psicanalítico, corresponde a um prazer sexual que não se confunde com o alívio de saciar a fome, ou seja, não é da ordem da necessidade. Alívio e prazer, ao alimentar-se, estão associados, mas o prazer sexual de sucção logo se transforma numa satisfação buscada por si mesmo, fora da necessidade natural. O bebê continua a sugar, mesmo saciada a fome, por descobrir que mamar é, em si, uma fonte de prazer.

Fazendo uma transposição para etapas posteriores, na vida adulta e na velhice, essa compreensão nos leva a afirmar que o prazer sexual - diferentemente do prazer orgânico, que é polarizado em torno de uma zona erógena e obtido graças à mediação de um objeto fantasiado - é encontrado entre os diferentes prazeres, das preliminares ao coito em si (prazer de olhar, de se mostrar, de acariciar, de sentir o cheiro do outro, etc.). Por isso, podemos 
condensar as etapas do prazer orgânico no nosso primeiro objeto sexual, que é o seio materno. Isso se verifica, por exemplo, no ato de beber o leite materno, no prazer de mamar no seio, no de chupar o polegar, no de abraçar o corpo amado, o que justifica a afirmação de que o seio materno é nosso primeiro objeto sexual.

Segundo Lacan (1973, p. 167): “[ . . . ] a sexualidade só se realiza pela operação das pulsões, no que elas são pulsões parciais, parciais em relação à finalidade biológica da sexualidade." Segundo este autor, a integração da sexualidade à dialética do desejo é atravessada pelo aparelho psíquico, no qual a pulsão representa a parcialidade da curva de terminação da sexualidade no ser vivo, ou seja, a presença do sexo está ligada à morte, num circuito de reversibilidade contínua no percurso pulsional. A satisfação da pulsão independe da satisfação da realização biológica que seria a satisfação de seu fim reprodutivo. A pulsão é sempre parcial, tendo como alvo apenas o retorno em circuito. A passagem da pulsão de uma fase à outra, ou seja, da pulsão da fase oral para a anal ou fálica, não está determinada pelo desenvolvimento, como uma evolução, mas pela demanda de um Outro.

É de extrema importância poder pensar que a partir da redescoberta do sexo e do amor, o velho reconquista o lugar vital de homem e mulher e não mais o de velho, que tem como futuro o fim da vida. Novamente, é na relação com o Outro que está a importância da redescoberta do desejo de viver. As fantasias sexuais, sob forma de sonho, ou sublimadas em expressões artísticas, retomadas na relação direta de namoro ou na relação com os familiares, netos, bisnetos, amigos, recolocam a vida viva, independentemente da idade ou da limitação física do velho. A capacidade de amar não tem limite cronológico. O limite está no psicológico, no preconceito e na intolerância social. O limite não está no real do corpo, ou na capacidade de sonhar, de simbolizar, de viver a vida.

Objetivamos, neste trabalho, analisar os sentidos do discurso dos velhos com relação ao amor e a sexualidade em suas vidas, através da interação da psicanálise com a análise da produção dos sentidos na perspectiva discursiva; a sexualidade e o amor na velhice, em suas manifestações erótica e afetiva.

Visamos ainda compreender os aspectos inconscientes que estão em jogo no discurso das participantes da pesquisa, com relação à sexualidade e ao amor, das primeiras experiências vitais até o período atual, como funcionam e 
se apresentam os efeitos discursivos, em relação às implicações sociais, culturais e subjetivas, que contribuem para o reconhecimento da heterogeneidade mostrada e para a não-coincidência do dizer, no que diz respeito aos sentidos e significados que apresenta essa produção discursiva.

\section{Aspectos Metodológicos}

O estudo que desenvolvemos utilizou-se da Análise do Discurso (AD), criada a partir da década de 60 por Michel Pêcheux, que se apresenta como um marco de mudança tanto em relação à análise de conteúdo como em relação à linguíística até então desenvolvida. $\mathrm{A} A D$ vai substituir a forma de análise de conteúdo tradicional através do estudo semântico proposto por Ferdinand de Saussure, que excluía do seu objeto de análise a exterioridade, ou seja, o que está fora, o que para a $\mathrm{AD}$ será o interdiscurso, a condição de produção, a formação discursiva.

Leite (1994, p. 113) afirma que " [ . . . ] sendo a fala um ato individual de uso da língua, e opondo-se para Saussure dicotomicamente ao sistema, é evidente que parte do resíduo se refere à noção de um sujeito livre, correlato ao avesso do sistema."

Segundo esse entendimento, a língua, como objeto da lingüística, é pensada como homogeneidade, enquanto a linguagem é heterogênea. Sendo considerada distante da fala, a língua é estudada em separado; renunciando à fala, a lingüística abre mão daquele que a opera: o sujeito. Pêcheux (1997a), ao iniciar o estudo da lingüística, baseia-se no ato inaugural de Saussure, mas estabelece relações entre o objeto língua e os mecanismos discursivos. Nessa perspectiva, a AD3 pêcheutiana ${ }^{4}$ baseia-se em mediações interdisciplinares para explicar os fenômenos discursivos, para a qual a psicanálise freudo-lacaniana contribui particularmente na concepção de sujeito, para a teoria do discurso enquanto sujeito do inconsciente, que se estrutura como uma linguagem.

A contribuição epistemológica da AD, segundo Pêcheux (1997b), reside na articulação de três regiões, quais sejam: o materialismo histórico, a linguiística e a teoria do discurso. A psicanálise é introduzida como uma teoria da subjetividade que atravessa os três campos. A noção de sujeito, a construção de sentido e a AD como "gesto" de interpretação entre AD e psicanálise

${ }^{4}$ Terceira fase da Análise do Discurso. Pêcheux abandona a noção de formação discursiva e emergem novos procedimentos. 
terá inspiração em Althusser (1992) no momento em que este faz a leitura do marxismo e propõe o sujeito como aquele que é interpelado pela ideologia, aproximando-a do modo de funcionamento da ideologia no pólo do sujeito ao inconsciente psicanalítico.

Quando Althusser (1992) afirma que a ideologia chama os indivíduos de participantes, Pêcheux (1997b) passa a articular a questão do sujeito e do sentido a partir do paralelo entre a evidência do sentido e a evidência do sujeito, em que o sujeito, no discurso, é definido por uma evidência de sentido. A origem real de onde provém o sentido é identificada imaginariamente como uma fonte, ou seja, se é produzido como sentido, dele não pode ser causa.

Para este trabalho, tentando fazer a intersecção possível entre a AD de terceira época de Pêcheux e a psicanálise, trabalharemos com as noções teóricas de heterogeneidade (AUTHIER-REVUZ, 1998) e com o interdiscurso pensado pelo próprio Pêcheux. Da psicanálise freudo-lacaniana, trabalharemos com os conceitos de sujeito do inconsciente como o Outro e a denegação.

Teixeira (2000) aponta que Pêcheux nos anos 80 discute a possibilidade de uma articulação com Authier-Revuz, com vistas à construção de um procedimento de análise de discurso, tomando as formas do dizer, lingüisticamente marcadas, e a dimensão do já-dito, noção marcada em superfície, constitutiva do sentido. A partir daí, é possível a tematização das formas lingüístico-discursivas do discurso-outro: discurso de um outro, conceito esse que será fundamental para a $\mathrm{AD}$ a partir de então.

Ao afirmar que as palavras são as palavras do Outro, isso significa que o discurso não se reduz a um dizer explícito. O Outro fala através do falante, e o dizer não corresponde ao enunciado de quem fala. A ruptura do discurso denota a heterogeneidade discursiva. Dizendo de outra forma, a heterogeneidade discursiva significa que todo discurso é atravessado pelo discurso do outro e, ainda, por outros discursos. Esses discursos mantêm entre si relações de contradição, de dominação, de confronto, de aliança ou de complementação.

Quanto à psicanálise, ela contribui para o estabelecimento de uma teoria do sujeito que pode situá-lo fora da dimensão cartesiana ou idealista, parecendo desse modo apropriado como solução aos impasses da $\mathrm{AD}$ no que se refere à questão do sujeito. Tomando como fundamentação esses dois cam- 
pos, a análise do discurso e a psicanálise, esta pesquisa se ocupa de trabalhar os efeitos de sentido produzidos pelas formações discursivas manifestadas pelos participantes entrevistados, com relação ao tema da sexualidade e do amor na velhice.

\section{Participantes}

Foram pesquisados três participantes residentes em Porto Alegre, entre 68 e 73 anos, tendo em comum os seguintes fatores: serem mulheres, estarem vivendo sem um companheiro, sendo duas viúvas e uma divorciada, todas possuindo, portanto, uma história de casamento e construção familiar.

Optou-se por investigar, num primeiro momento, participantes femininos, devido ao fato de essa população ser maior em relação à população masculina, o que é um dado significativo, tendo em vista ser esse um fenômeno mundial. Além disso, considerando que esse excedente implica que as mulheres tenham que buscar formas de resolução para uma situação de solidão que pode estar relacionada a uma escolha de nunca ter tido um companheiro ou, ao longo de sua vida por terem enfrentado situações de perda definitiva, ou seja, por morte do companheiro, ou rompimento por separação da convivência com o mesmo.

Nosso interesse, ainda, tem como foco trabalhar com conceitos psicanalíticos, que buscam uma compreensão da sexualidade do ponto de vista psicossexual, tendo em vista que ser homem ou mulher, biologicamente, não determina sua constituição subjetiva. Será por via dos processos identificatórios construídos nas relações objetais que se definirá a identidade sexual e assim aparecerão as implicações dessa escolha na condição do seu papel social. No presente trabalho, os participantes fazem parte dos que optaram por uma escolha heterossexual, não por uma escolha arbitrária de nosso universo de pesquisa.

\section{Instrumentos}

Foram realizadas entrevistas semidirigidas com o objetivo de orientar as questões relativas à sexualidade e à vida amorosa, revisando a trajetória de vida das participantes de forma que essa rememoração tivesse um caráter puramente de reconstrução histórica, sem intervenção de cunho interpretativo 
ou terapêutico por parte do pesquisador. Essas entrevistas semidirigidas foram realizadas individualmente para coleta de dados, constando dos seguintes itens:
a) vida sexual e vida amorosa;
b) período aproximado das suas primeiras experiências amorosas e/ou sexuais;
c) o que mudou na vida amorosa e sexual da idade adulta para a velhice;
d) como pensa que seus familiares e/ou amigos encaram a sexualidade $\mathrm{e}$ o amor na velhice.

Informou-se que a entrevista seria gravada em fita de áudio para posterior transcrição de alguns trechos referentes aos objetivos do trabalho, sendo mantido o caráter sigiloso no concernente à identidade dos participantes. Para isso, os nomes dos próprios participantes e de pessoas, lugares e cidades mencionados, foram mudados.

Foi também comunicado que esses dados seriam objeto de estudo e discussão em uma dissertação de mestrado. Solicitou-se a assinatura de um termo de consentimento informado. Os nomes usados nos relatos dos depoimentos são fictícios.

Nessa análise, propomo-nos um olhar discursivo sobre o material lingüístico obtido em sua heterogeneidade, sem preocupação com um rigorismo formal de análise das marcas lingüísticas. Buscamos relacionar sentidos manifestados pelas participantes com sentidos pré-construídos socialmente, constatando o modo peculiar com que o sujeito os significa, dando voz ao inconsciente, ou seja, à emergência do desejo via deslizamento significante, seguindo um entendimento psicanalítico.

\section{Demarcação e Exercício de Análise do Corpus}

Seguindo a visão da escola francesa, a Análise do Discurso (AD) é considerada como uma disciplina de interpretação. A leitura do corpus buscou evidências, efeitos de sentidos discursivos produzidos pelas participantes nas entrevistas referentes às questões da sexualidade e do amor, em uma retrospectiva histórica de suas vidas. No decorrer do exame das entrevistas, foram identificadas palavras ou expressões no fio do discurso que apresentam significados que indicam a passagem do tempo, caracterizados como enunciados discursivos que situam o idoso como "velho", preconceituosamente, mas, 
heterogeneamente, mostram-se também sentidos diversos, como se houvesse um tempo determinado para o desempenho de cada papel.

Considerou-se:

a) relação ideal: o que o sujeito refere como os comportamentos esperados e aceitos socialmente;

b) violência: comportamento que implica agressão física e/ou verbal, o que envolve, de alguma maneira também as questões de preconceito e de julgamento moral;

c) sublimação: conceito psicanalítico que implica o mecanismo pelo qual a sexualidade é desviada de seu fim, buscando o sujeito satisfação em outras formas socialmente aceitas, como, por exemplo, em atividades criativas e artísticas, dentre outras;

d) denegação: conceito psicanalítico que implica a negação da negação, ou seja, o sujeito nega o que realmente deseja, o que equivale a dizer que, pela denegação, a insistência em negar é uma afirmação, mascarando negativamente a repressão.

Buscando estabelecer algumas intersecções entre $\mathrm{AD}$ e psicanálise, considera-se a questão da interpretação no sentido desses dois campos, partindo do princípio que eles não foram fixados a priori. O que se buscou nesta investigação foram questões referentes à compreensão da concepção de sujeito do discurso e do inconsciente.

O sujeito do discurso não deve ser confundido com a ideologia nem com o inconsciente, mas deve ser entendido a partir da relação entre eles. Lacan (1973) vai inspirar a perspectiva de Authier Revuz (1990), apontando para a existência de uma fala heterogênea, polifônica, de um sujeito dividido, de onde emergem os significantes inconscientes da língua. Para Authier-Revuz (1990, p. 28), a “[ . . . ] concepção do discurso atravessado pelo inconsciente se articula àquela do sujeito que não é uma entidade homogênea exterior à língua: sujeito descentrado, dividido, clivado", o que reforça a concepção lacaniana de que o sujeito não se constitui através de uma fala homogênea, posto que o sujeito é clivado, inserido no campo do Outro, é marcado pelo desejo do Outro.

Quando Lacan (1973) postula que o inconsciente é estruturado como uma linguagem, tem presente que essa linguagem é marcada pela prevalência do significante sobre o significado e prioriza o deslizamento do significante que, por ser referido ao que o sujeito representa para um outro significante, 
está sempre referido a um Outro, a um sujeito clivado, que busca um ideal imaginário, um encontro com um objeto sempre faltoso.

Recorremos aqui, ao que diz Carolina, ${ }^{5}$ uma participante da pesquisa, a título de exemplo: “[ . . . ] eles não estavam ali pra dançar, como era o meu propósito, né, de passar uma noite agradável. E no começo eu fiquei muito chocada."

O encontro faltoso com o objeto significa que, na relação com o Outro, se repete, imaginariamente, o enamoramento. Buscamos corresponder ao desejo que, supomos, o Outro tem em relação a nós. Por isso esse desejo é impossível de realização, porque esse desejo que supomos revela que o que se deseja é o desejo do Outro, daí a impossibilidade de encontro. Devido a isso, o sujeito é descentrado, ao mesmo tempo em que, por ser clivado, castrado, é possível constituir-se enquanto sujeito.

É por essa impossibilidade de encontro, por não corresponder ao que supõe que o Outro quer dela, que pode se constituir enquanto sujeito, ou seja, é diferente, tem também desejos que a distinguem. Não é um objeto à disposição para qualquer coisa. O que a diferencia é o que lhe dá identidade, o que permite nomear-se enquanto ser desejante: “[ . . . ] eles não estavam ali pra dançar, como era o meu propósito [ . . . ].” Aí então descobre seu propósito.

\section{Os Efeitos de Sentidos Discursivos}

Tomo como elemento de análise os efeitos de sentidos produzidos no discurso, no qual os participantes referem como comportamentos esperados e aceitos socialmente, dentro do seu contexto. A relação ideal aqui pode ser entendida como uma formação discursiva (FD), correspondendo à ideologia patriarcal determinando um lugar a ser cumprido pela mulher.

O foco da análise é colocado no processo de construção de uma identidade da moça de família que respeita os valores tradicionais: educada para casar virgem, ter filhos, dedicar-se inteiramente aos cuidados, à manutenção e à educação dos mesmos e dependente economicamente do marido, que é o chefe e provedor.

Para as entrevistadas, parece que não foi colocada nenhuma questão sobre essas determinações sociais até o momento em que o casamento se manteve, ou seja, a identidade dessas mulheres estava definida a priori pela determinação social. O que aparece na formação discursiva é a realização de

${ }^{5}$ Conforme informado anteriormente no item 5, todos os nomes utilizados para identificar as participantes são fictícios, os quais foram inspirados em músicas de Chico Buarque.

Estud. interdiscip. envelhec., Porto Alegre, v. 5, p. 57-80, 2003. 
um ideal de casar, ser mãe, cuidar da família, não podendo reconhecer outros valores que não os instituídos por esse contexto. Os discursos das participantes estão construídos a partir de um interdiscurso, sem que elas se apercebam de sua implicação enquanto participantes dos papéis e lugares sociais que assumiram.

Observa-se aqui o que Orlandi (2001, p. 91) aponta, isto é, a forma sujeito histórica que corresponde à nossa forma social é a de um sujeito dividido. As mulheres entrevistadas, ao mesmo tempo em que parecem livres de suas escolhas - determinando o que dizem, como contam suas histórias - são determinadas pela exterioridade (algo fala de outro lugar, fora de seu alcance de determinação), algo fala de um lugar de seu assujeitamento, de sua condição social. Isso se revela na seqüência de formações discursivas que se seguem:

"Sempre fui muito namoradeira, desde moça [ . . ] só não deixava chegar perto. [...] tudo foi superbem até a ruptura do casamento [...] fiquei cinco anos sem me achar, sem de jeito nenhum [... ] só queria morrer, só não fazia besteira por causa dos filhos. "Casei virgem, isso era uma coisa absoluta, meu Deus o livre [... ] namorei e casei com 21 anos."

No que diz respeito a esse primeiro item, relação ideal, as partes em itálico revelam como os participantes seguem os valores que parecem colocar a mulher em um lugar instituído dentro de uma seqüência, ser mulher devota ao marido, dona de casa e mãe.

As participantes seguem uma história de vida tradicional: casam, são apaixonadas pelos maridos, chefes e senhores que resolvem todos os problemas que dizem respeito à sua sobrevivência. Lígia, a primeira entrevistada, sente-se enlouquecida quando o casamento termina, pois o marido abandona o lar; só quer morrer, perde o sentido, como se não tivesse mais um referencial identificatório, precisa recorrer à internação por entrar em depressão. Só os filhos a impedem de cometer uma loucura, é o que diz. Essa situação desesperada só pode ser conseqüência de uma situação de dependência absoluta. Lígia acreditava que tudo estava como era mandado, sendo apanhada de surpresa, pois não sabia nem assinar cheque. Teve que dar conta da própria vida e da vida dos filhos, voltar a estudar e procurar um trabalho.

Carolina, a segunda entrevistada diz que trabalhou até o nascimento do segundo filho, quando o marido achou que ela deveria ficar em casa cui- 
dando dos filhos. Sempre moraram com a mãe e com a sogra. Ela conta que sua vida não foi um "mar de rosas", embora não mencione o tipo de problema que possa ter tido, apenas aponta que teve muitos altos e baixos porque tinha uma família grande. Conta que viajava muito com o marido e que se entendiam bem. Ela gostava de cuidar das roupas dele, engomando ela mesma seus ternos. Diz que o adorava.

Rita, a terceira entrevistada, diz que os filhos temiam o marido, que era muito severo com eles, mas que com ela se transformava. Ele era romântico e delicado e fazia suas vontades. Só não se entendiam em relação à educação dos filhos, porque ele não desculpava nada. Quando ele morreu, a sogra foi morar com ela e os filhos.

Mantendo o discurso de relação ideal, Carolina e Rita, após a morte dos maridos, permanecem cuidando dos filhos e morando com as sogras, não voltando a casar. Carolina continua com a mãe e a sogra a seu encargo, afirmando que adorava a sogra e que sente muita falta dela, assim como de sua mãe. Nunca havia se imaginado com outro homem. Todo o amor que tinha pelo marido transferiu para os filhos e, depois, para os netos. A insistência em usar o verbo "adorar" parece ritualizar a relação com o marido, com a sogra, com os filhos, com os netos, como se amar implicasse algo sexualizado. Mas, contrariamente ao que transparece, como dedica sua vida a cuidar das pessoas da família, o termo "adorar" apresenta-se como uma devoção ou vocação, dessexualizado.

Quanto a Rita, quando o marido morreu, ficou cuidando dos filhos e da sogra, com quem sempre se deu muito bem, assim como com sua mãe. A sogra era muito ciumenta e preocupava-se com a nora, que só saiu para divertir-se com amigas depois de pedir sua permissão, nove anos depois da morte do marido.

O segundo item que se destaca como efeito de sentido manifestado no discurso das participantes entrevistadas é a violência física, explicitada por Lígia quando se refere à agressão sofrida por parte de seu último companheiro. Conta que ele era impotente, mas que isso não tinha importância para ela, considerando que o que ela queria era uma companhia. Ele era muito carinhoso, atencioso, mas, com o tempo, foi ficando grosseiro e, certo dia, tentou estrangulá-la.

A referência à agressão física remete a outra situação anterior, com um companheiro com quem havia vivido por 10 anos e que também tentou 
estrangulá-la. Afirma que esse homem era um louco, mas que, se ele não tivesse morrido, talvez ainda permanecesse vivendo com ele. Apesar de ter enfrentado a situação de separação e tentado recomeçar sua vida amorosa, reflete uma insistência das questões de submissão à figura masculina. Quando afirma que, se o companheiro não tivesse morrido, teria continuado ligada a ele, mesmo que a maltratasse, revela seu assujeitamento à figura masculina, a um discurso outro. $\mathrm{O}$ fato de reviver essa situação agora a fez romper o relacionamento com o último namorado, dizendo não querer mais ser mulher de ninguém, embora fosse ativa sexualmente igual a sempre, desde que correspondida pela outra parte.

Lígia havia estado casada por muitos anos, teve cinco filhos, e foi abandonada pelo marido. A separação a enlouqueceu, foi parar em hospital psiquiátrico, precisou recorrer a tratamento com medicação e análise. " [ ... ] tudo foi super bem até a ruptura do casamento [... ] fiquei cinco anos sem me achar, sem de jeito nenhum [ . . . ] só queria morrer, só não fazia besteira por causa dos filhos."

Quando venceu a crise, enfrentou a vida tentando romper com os padrões familiares com os quais tinha vivido. No processo de sua saída de casa para procurar emprego e diversão, depara-se com um assédio que não havia conhecido. Diz que não sabia como os homens tratavam as mulheres "lá fora”, mas isso não a impede de enfrentar a nova situação, ou seja, procurar atualizar-se, estudar, trabalhar, ter namorados, recuperar a vida. Depara-se com situações em que tem de reavaliar o que encontra na nova relação e o que pode suportar. Conta que: "[ . . . ] queria alguém que falasse a mesma língua minha, que era isso que eu queria, uma pessoa para trocar idéias, vamos sentar, vamos conversar, vamos até rir juntos".

Parece que, ao se recuperar da situação de separação do casamento, busca refazer sua vida amorosa nos mesmos moldes ideais anteriores. No entanto, as novas relações que encontra se mostram distintas dos padrões colocados como o ideal que acreditava existir, pois as pessoas têm dificuldades sexuais, não têm o mesmo nível cultural.

Agora, com a revivência da agressão física pelo último companheiro, Lígia parece desistir das tentativas amorosas. Diz que chegou a hora de ser mãe, avó, amiga, mas não mais mulher de ninguém, como se houvesse uma incompatibilidade de papéis. 
Outro efeito de sentido que se produz nas formações discursivas dos participantes diz respeito ao preconceito que encontraram em relação à sua vida ativa e à sexualidade. Para Lígia, o preconceito veio de muitas formas, relata que sentiu muito a crítica das pessoas (embora não revele de quem) no sentido de ser vista como sem-vergonha, ou "puta", nas palavras dela, por sair para divertir-se. Com relação a seu último namorado, agora com 69 anos, a relação foi escondida do filho porque temia que ele contasse a seu pai, embora já estivessem separados e o seu ex-marido já estivesse com outra família. Suas filhas não se importavam muito, ou seja, importavam-se um pouco, mas como esse namorado estava dando um apoio num momento difícil na vida de Lígia, elas não intervinham.

Quando perguntada sobre ter encontrado preconceito por parte de amigos ou familiares, diz: "Olha, encontrei, encontrei na família. O filho não sabia do $C$ (companheiro). Ele ia correndo contar pro pai dele. As gurias não, não ligam muito."

Com relação à Carolina, o preconceito revela-se em seu próprio discurso, quando diz que não falava com sua mãe sobre sexualidade e que foi para o casamento com informações das amigas. Assim como não tinha intimidade com a mãe para falar desses assuntos, reproduziu o mesmo com sua filha e sente-se chocada com a evolução das relações de namoro de agora de seus netos, principalmente de suas netas. Durante toda a entrevista, menciona apenas uma vez a palavra sexo. Sentia-se envergonhada em relação às netas dormirem com os namorados e à possibilidade de suas amigas descobrirem. Também não se conforma pelas mesmas não falarem em casamento, em terem família. Ela própria, depois da morte do marido, nunca havia se imaginado com outro homem, embora diga que não condena as suas amigas que querem namorar.

Ao ser perguntada sobre o que sabia sobre sexo antes do casamento, relata: "Não, a mãe nunca, Deus nos livre, a mãe nunca, nada, o que eu sabia era das amigas de colégio [... ] também nunca falei com a minha filha."

Nesse relato, o que aparece é o preconceito da própria entrevistada em relação às questões da sexualidade, no que diz respeito à sua própria orientação, proibida de informar-se ou de confidenciar suas dúvidas e temores com a sua mãe e tendo que ouvir as histórias contadas pelas colegas. $\mathrm{O}$ preconceito aparece como parte da sua própria compreensão da realidade, 
tendo ela incorporado o discurso de seu meio cultural, não se sentindo com liberdade de enfrentar o tema com sua própria filha. Fica ouvindo a conversa dos jovens com quem, segundo ela, aprende muito, e acha que agora é que está certo, embora não saiba dizer por quê.

Rita, a terceira a ser entrevistada, revela uma submissão aos valores familiares. Após a morte do marido, dedica-se a criar os filhos e a cuidar da sogra, que passa a assumir o controle da vida da nora. Mostra-se ciumenta, controladora, vigiando os passos da nora que tem que dizer aonde vai, com quem sai. Ela enviuvou com 42 anos e só depois de nove anos da morte do marido é que conseguiu sair para festas, mas teve que pedir o consentimento da sogra.

Depois disso, teve namorados, mas nunca os apresentou ou contou aos filhos ou à sogra que estava namorando. Diz que só encontra homens que não valem nada, que querem se encostar, porque a vida de aposentado é difícil. Está desiludida, mas gostaria de uma companhia para sair. Diz: " [... ] eu tive namorados, né [ ... ] inclusive quando a minha sogra era viva, ainda. Mas ela não sabia e eu dizia que era um amigo [ . . . ] eu dizia, ah, eu conheci num baile, eu nunca disse namorado."

Carolina conta suas experiências nas festas e bailes, parecendo que ainda esperava encontrar a situação de quando ia às "reuniões dançantes" de quando conheceu seu marido. Diferentemente, a abordagem dos homens era de forma direta, querendo saber sua situação econômica e se era separada ou viúva. Eles a chocavam, como se quisessem só se aproveitar dessa aproximação para usufruir de sua condição financeira. Não era tratada com romantismo e consideração, como seu marido fazia em vida. Acha os homens sem criatividade, pois eles dizem coisas vazias, são interesseiros. Parece continuar presa ao sonho de adolescente, querendo se enamorar, ser cortejada. Ao ser tratada como uma mulher, e não como uma mocinha, e abordada diretamente para o sexo, ou interrogada sobre sua condição econômica, fica desiludida, o que a leva a desprezar os homens. No entanto, diz que sente falta também de ter relações sexuais com alguém.

A sublimação revela uma das formas que as participantes encontraram para dar conta da sexualidade. Embora em nenhum momento das entrevistas apareça a compreensão de que a realização libidinal que buscam se manifesta através do desvio para o cuidado com outras pessoas, quer seja a mãe, a sogra, os filhos, os netos, amigos, isso não é considerado uma saída 
para a sua sexualidade. A exemplo dos valores culturais a que estão submetidas, parecem entender sexualidade apenas como descarga genital.

Lígia, quando perguntada sobre o que ainda lhe dava prazer, responde:

"[... ] a única coisa que eu ainda gosto é estar com os netos, junto com os netos, os filhos às vezes. A única coisa que eu dou risada, que eu brinco, que eu fico feliz, é com os netos. Mais nada, nada, nada [ . . . ] eu acho que quando a gente é mais velha se completa mais do que quando é moça (em relação ao sexo), tu te sente mais plena, quanto mais o tempo passa, parece que tu... as coisas pra mim, mesmo com um parceiro com problemas e tudo eu achava assim que o conteúdo, tudo, o carinho [...] com o C. tive tudo isso [... ], aquela camaradagem dele e aquilo tudo foi muito bom pra mim. [...] Eu me sentia realizada como mulher, mesmo que não [... ] o sexo da parte dele não fosse satisfatório. Mas eu acho superválido quando as pessoas se acertam, que eu acho que tem tudo para ser feliz."

Os efeitos de sentidos produzidos por Lígia apontam para a sublimação, na medida em que vê a relação com os parentes - e mesmo com um companheiro - como algo gratificante. A satisfação que encontra está ligada ao sentido da camaradagem, do carinho, do cuidado, da troca com o outro e à satisfação do próprio contato afetivo, para além do sexual genital, sentindo-se realizada como mulher.

Já para Carolina, o caminho foi mais voltado para os cuidados com a família, não pensando ela em reconstruir a vida com outro companheiro. Depois da morte do marido, dedicou-se inteiramente aos cuidados da mãe, da sogra e dos netos, estando sempre presente quando os pais das crianças viajavam, levando-os a aulas especiais, convivendo com eles nas férias. $\mathrm{Na}$ medida em que mãe e sogra morrem, os netos crescem, ela vai ficando mais sozinha. Por morar sozinha, a solidão começa a pesar. Nesse momento, ela busca o grupo de convivência de terceira idade e diz que se dá bem. A partir daí, faz viagens, passeios, tem participação ativa na entidade oficial que trabalha, no Conselho Municipal do Idoso (CMI). No entanto, não acha que essas atividades impliquem investimento libidinal, ou seja, que sejam atividades que lhe dêem prazeres substitutos da atividade sexual genital.

Depois da morte do marido, Rita resolve sua vida sexual dedicandose à família e, ao mesmo tempo, retomando o convívio com amigos e namorados, embora nunca tenha conseguido assumir um companheiro perante a família nem reconstituído uma relação amorosa duradoura.

A solução para sua vida sexual tem duas direções: a primeira é a de 
cuidar da família, filhos e sogra, o que, de certa forma, dá uma continuidade à relação construída com o marido, já que a sogra dirige sua vida, suas saídas, mantendo um certo controle sobre sua vida sexual, ao ponto de ela afirmar para a sogra que não pretende mais casar, mas apenas ter amigos, distrair-se; a segunda é a de namorar escondido, apaixonar-se, mas, uma vez descobrindo que sua paixão é um homem casado, desfaz o namoro, pois não poderá apresentá-lo à família, já que não se sentiria bem com a situação (de ele ser casado). Aqui parece o modelo referencial como do tempo ainda de solteira, ou seja, apresentar o namorado à família ou pedir permissão para namorar.

Outro efeito de sentido que emerge na formação discursiva é a denegação em relação ao interesse sexual, quando os participantes negam aquilo que realmente desejam. Do ponto de vista psicanalítico, essas oposições discursivas apontam para os significantes que insistem. Via denegação, Lígia tenta impedir o jogo de forças pulsionais com a repressão. Ao afirmar que o fato de seu companheiro ser impotente não ter importância para ela e que, ao mesmo tempo, ela continua ativa sexualmente, desde que correspondida, há o apontamento para uma negação da negação.

"[... ] com problemas sexuais, que também pra mim não era importante, não era importante, não era importante porque eu achava assim que eu sabia, apesar de eu ser sexualmente ativa, igual, eu sou até hoje, não tenho problema nenhum, claro se correspondida, né [... ]".

Negar reiteradamente que a impotência não tem importância é o mesmo que afirmar que isso produz sintomas nela também, pois se diz ativa sexualmente "claro, se correspondida". Isto equivale a pensar que a impotência do outro a afeta, já que não se sente correspondida em sua demanda sexual, o que pode frustrá-la, deixá-la com sentimento de impotência. O retorno aparece em forma de desqualificação do homem, que é "[ . . . ] burro, surdo, impotente e agressivo."

Segue-se a essa afirmativa outra igualmente em contradição, quando ela afirma em outra formulação discursiva: "Eu não tenho mais vontade nenhuma de começar nada mais, eu acho que agora chegou a vez, assim, de eu ser avó, a mãe, a amiga, tudo, mas menos mulher de ninguém [ . . . ] eu acho."

Lígia parece colocar em oposição, ou como incompatível, a possibilidade de ser avó, mãe, amiga e de ser mulher para um homem. A sua desilusão, com conseqüente desqualificação dos homens, faz com que pareça es- 
tar cansada para tentar reiniciar qualquer relação amorosa. No entanto, ao concluir sua frase dizendo "eu acho", revela a denegação dessa afirmativa, como se ainda não fosse totalmente conclusiva essa decisão.

Para Carolina, o fato de ter ficado viúva parece ter reforçado os aspectos repressivos decorrentes de sua formação, negando qualquer interesse sexual em relação a outro homem.

"E depois que eu fiquei viúva, assim, é uma coisa, assim, que vejo as minhas colegas, assim, que eu não desaprovo isso que gostam de namorar, mas é uma coisa que nunca me chamou a atenção. [ . . . ] Eu não me imagino, acho que foi muitos anos assim... eu não me imagino, eu com outro homem. Agora eu tô muito velha mesmo, mas mesmo mais moça, eu não me imagino, entendes?"

Ao construir essas afirmações, revela que em algum momento, ao ver suas colegas se interessarem em namorar, pode lhe ter feito uma questão: por que não eu? Ela afirma que não desaprova, mas que é uma coisa que nunca lhe chamou a atenção. Contudo, mencionar o fato pode revelar que, no mínimo, ela pensou sobre essa possibilidade ao ver que as pessoas com as quais convivia se permitiam retomar a vida amorosa e sexual.

Da mesma forma, nega imaginar-se com outro homem, pois passou tanto tempo casada com o mesmo homem. Para não conseguir se imaginar em outra relação, no entanto, precisou seguramente fantasiar sobre isso chegando a dizer que agora já está muito velha. Isso significa dizer que quando mais moça isso já lhe ocorria, mas é preciso negar, como para manter fidelidade à sua formação familiar e ao que supõe ser seu papel enquanto avó, mãe e filha - tanto que ficou encarregada de cuidar da mãe e da sogra - e só começou a participar de encontros e festas com o grupo de terceira idade, como chama, após a morte das duas e quando não havia mais netos para criar.

Rita fala de suas experiências como se estivesse aberta para recomeçar, ao mesmo tempo em que desqualifica os homens, para manter sua posição de viúva e fiel ao marido, por quem diz continuar apaixonada até hoje, depois de todos os anos passados. São suas as afirmações:

"[ ... ] alguns eu cheguei a mais intimidade, né, mas eu vi que não valia a pena, que eu tava ali com uma pessoa que não tinha nada a ver comigo [ . . . ] porque o sexo eu fui tão feliz no casamento que eu acho que o sexo, não é ir pra cama só por causa do sexo, tem que ver um sentimento um pouco se não é uma paixão." 
Para Rita, ser admirada nos bailes, chamar a atenção, dançar apertado, deixam-na muito feliz, segundo conta, pois é sinal de que ainda agrada a alguém. Parece que essa constatação é suficiente para se sentir desejada, mas não consegue levar a cabo sua conquista, desqualificando os homens, como se fossem interesseiros, sem criatividade, como se nenhum despertasse seu desejo como o marido, que a cortejava, seduzia e sustentava, com quem era ativa e gulosa. Pensa que os homens agora só pensam em saber da situação econômica das mulheres, para poder se "encostar". Por isso, reprime-se e não se entrega, mas não deixa de freqüentar bailes e de arrumar-se para chamar a atenção e receber elogios e propostas amorosas, as quais nega, pois nenhum homem vale a pena como seu falecido marido, com quem foi muito feliz.

\section{Conclusões}

Trabalhar o tema do amor e da sexualidade na velhice usando como referencial teórico a psicanálise é plenamente justificável, considerando que a psicanálise freudiana baseia-se na assíntota entre sexualidade e linguagem. Desde seus estudos iniciais sobre as pacientes histéricas, Freud observava que a excitabilidade do histérico, de um lado, e a não-congruência, a nãoadequação dessa excitabilidade ao pensamento, do outro, assim como a ausência de junção dos dois planos, deixavam à mostra que a linguagem atestava o abismo entre as duas margens. Para esse autor, a excitação não corresponde ao pensamento, tanto que não se pode dizê-la. É pela linguagem que as duas margens da excitabilidade traumática podem se expressar sem o saber, de forma inconsciente.

Do ponto de vista lacaniano, as palavras instauram-se e deslocam-se na dimensão da verdade, e, em sua presença, não sabemos se elas são verdadeiras ou não, pois elas estão situadas no registro do erro, do equívoco, da mentira. A função significante das palavras faz-se pela relação que elas têm com as outras palavras.

Através da análise da produção de sentidos na perspectiva discursiva das entrevistadas sobre a sexualidade e o amor na velhice, juntamente com a psicanálise, identificamos a leitura freudiana quando o autor afirma que a heterogeneidade do inconsciente não é mais que uma resposta teórica à posição de alteridade do desejo, vinculada ao desejo do Outro e ao lugar do código. Em contrapartida, o efeito de significação da consciência produz-se 
sempre em detrimento de um efeito de sentido, ou seja, a significação de uma palavra em um discurso supõe o recalque dos sentidos que esta palavra poderia ter em outro discurso. Quando o sujeito fala com seu semelhante, fala em uma linguagem comum, que considera os “eus" imaginários como coisas não unicamente ex-sistentes, porém reais.

Essa afirmação evidencia que as participantes da pesquisa, embora tenham se disposto a rompimentos com o discurso oficial apreendido ao longo da vida desde a estrutura familiar e patriarcal, embora ao longo de suas vidas tenham passado por mudanças de valores em relação ao sexo, ao amor e ao relacionamento afetivo - convivendo com essas transformações dentro da própria família que elas constituíram - revelaram, em seus discursos, sua disposição para uma vida sexual permeada pelas fantasias. Duas dessas participantes mantêm o ideal de uma vida amorosa, com um companheiro estável e constante. Uma terceira participante desloca essas fantasias, passando a ouvir as histórias contadas pelos netos jovens, com a expectativa de que também eles busquem o sonho de formar família, casar e ter filhos.

Ao pesquisar os efeitos de sentidos do discurso produzidos pelas entrevistadas com relação ao tema do amor e da sexualidade na velhice foi possível identificar o atravessamento pulsional que se revela nas afirmações, negações e denegações das experiências relatadas. A reconstrução histórica de suas vidas, revelou o que estava oculto por trás das afirmações, ou seja, que as participantes da pesquisa resolveram suas questões relativas à vida efetiva e sexual pela possibilidade dos deslizamentos inconscientes, via fantasia, o que permitiu a sustentação de se sentirem amadas pelos familiares pela dedicação aos cuidados dos mesmos - quer sejam os filhos, os netos, os amigos; ou via amorosa e/ou via relação amorosa e/ou sexual, com namorados e companheiros.

O discurso analisado nesta pesquisa vai ao encontro do imaginário das participantes. O sujeito/imaginário apresenta-se através da linguagem nas ocasiões em que procuram mostrar discursivamente um sentido legítimo e transparente, acreditando terem uma autonomia de serem donas de seu dizer. A linguagem, no entanto, pela sua incompletude, pela sua falha, sofre rupturas, sendo que aí o sujeito (do inconsciente) fala e se mostra, obrigando nossas participantes a negociarem com os outros sentidos que lhes são impostos pela heterogeneidade constitutiva, que intervém constantemente em suas enunciações. 
Pela "não-coincidência do dizer", verifica-se a impossibilidade de se dar conta da autenticidade dos sentidos das palavras. As palavras erram o alvo, falham, não dizem tudo. Aí identificamos o sentido do discurso como efeito no encontro do sujeito (desejante) com o dito, isto é, aquilo que está presente no aqui e agora da enunciação, o já dito, que é da ordem da ausência, que vem de outro lugar e atravessa o dito.

O discurso mostra, assim, na linearidade de sua cadeia, pontos de não-coincidências revelando a presença do Outro. Nessa perspectiva de análise, foi possível apontar as irrupções do sujeito na cadeia do sentido, desfazendo alguns trajetos nos quais ficam evidentes os efeitos de rupturas no discurso, cuja manifestação envolve a constituição heterogênea do sujeito discursivo, na tensão entre o dito e o já dito, na tensão entre o aqui e agora e o que já estava dado em outro lugar.

Finalmente, o sujeito do inconsciente, "estruturado como linguagem", é o sujeito constituído em uma fala heterogênea na divisão da relação entre consciente e inconsciente. O sujeito é, pois, determinado por um significante que é predeterminado por uma intersubjetividade.

O sexual insiste para além das questões biológicas, pois mesmo que organicamente, com a velhice, o ser humano tenha perdas de suas capacidades físicas, não perde a capacidade de sonhar, desejar e principalmente, de desejar viver. Poder desejar é o que nos distingue das outras espécies. Esse desejo possibilita o enfrentamento da idéia de que somos seres mortais.

\title{
SEXUALITY AND LOVE IN OLD AGE
}

\begin{abstract}
This paper is the result of the research on Sexuality and Love in Old Age. The objective is to analyze, through the interaction of psychoanalysis with the analysis of the production of significations, from the discoursive perspective, the aspects of sexuality from the pulsional point of view. For that, we analyzed the unconscious implications that are in game in that problem. As a methodological instrument we used the production of effects of significations based on Speech Analysis of the French school that has as founder Michel Pêcheux, more specifically, in that author's third phase, taking in consideration the theorization of Althier-Revuz, of Orlandi and of Teixeira. Also contributing to this work there are the foundations of Freud's
\end{abstract}


psychoanalysis reffering to the unconscious and sexuality, and of Lacan, reffering to the subject of speech in its relationships with the Other. We concluded that the subjects tied to sexuality and love in old age are revealed in discursive heterogeneity, with the non-coincidences of saying. Sexuality insists on coming in another way under the form of fantasies, desires and dreams. With old age the supposed waiver of a sexual and loving life is not verified, because this is pulsional, being for that reason an inexhaustible vital element.

Keywords: Sexuality. Old Age. Heterogeneity of Speech.

\section{REFERÊNCIAS}

ALTHUSSER, Louis. Aparelhos Ideológicos do Estado. Rio de Janeiro: Graal, 1992.

AUTHIER-REVUZ, Jacqueline. Palavras Incertas: as não-coincidências do dizer. Campinas: Ed. da UNICAMP, 1998.

BEAUVOIR, Simone. A Velhice. Realidade Incômoda. São Paulo: Difel, 1976.

FREUD, Sigmund. Três Ensaios sobre a Teoria da Sexualidade. Rio de Janeiro: Standard Brasileira: 1969. V. VII

LACAN, Jacques. O Seminário 11: os quatro conceitos fundamentais da psicanálise. Rio de Janeiro: Jorge Zahar, 1973.

LEITE, Nina. Psicanálise e Análise do Discurso: o acontecimento na estrutura. Rio de Janeiro: Campo Matêmico, 1994.

MANNONI, Maud. O Nomeável e o Inominável: a última palavra da vida. Rio de Janeiro: Jorge Zahar, 1995.

ORLANDI, Eni P. Discurso e Texto-Formulação e Circulação dos Sentidos. Campinas: Pontes, 2001.

PÊCHEUX, Michel. A Análise de Discurso: três épocas (1983). In: GADET, F. ; HAY, T. (Org.) Por uma Análise Automática do Discurso: uma introdução à obra de Michel Pêcheux. Campinas: Ed. da UNICAMP, 1997a. P. 311328.

Análise Automática do Discurso (AAD-69). In: GADET, F.; HAY, T. (Org.). Por uma Análise Automática do Discurso: uma introdução à obra de Michel Pêcheux. Campinas: Ed. da UNICAMP, 1997b. P. 61-162. 
SANCHEZ, Carmen Délia Salgado. Gerontologia Social. Puerto Rico: Publicaciones Puertorriqueñas, 1999.

TEIXEIRA, Marlene. Análise de Discurso e Psicanálise: elementos para uma abordagem do sentido do discurso. Porto Alegre: EDIPUCRS, 2000. 